\title{
Spontaneous rupture of continent cutaneous urinary diversion after 25 years
}

\author{
Seyed Yousef Hosseini ${ }^{1}$, Mehdi Dehghani ${ }^{1}$, Amin Afsharimoghaddam ${ }^{1,2^{*}}$,Zahra Sepehri ${ }^{3}$, Mahdi Afshari ${ }^{4}$ \\ ${ }^{1}$ Urology and Nephrology Research Center and Department of Urology, Shahid Beheshti University of Medical Science, Tehran, Iran \\ ${ }^{2}$ Department of Urology, Zabol University of Medical Science, Zabol, Iran \\ ${ }^{3}$ Department of Internal Medicine, Zabol University of Medical Science, Zabol, Iran \\ ${ }^{4}$ Department of Epidemiology, Zabol University of Medical Science, Zabol, Iran
}

\section{A R T I C L E I N F O}

Article Type:

Case Report

\section{Article History:}

Received: 18 September 2016

Accepted: 30 October 2016

Published online: 19 November 2016

\section{Keywords:}

Spontaneous rupture, Urinary

diversion, Cutaneous pouch,

Radical cystoprostatectomy

\begin{abstract}
A B S T R A C T
Spontaneous rupture of a continent cutaneous urinary diversion is uncommon and diagnosis of this situation requires a high degree of suspicion. In this paper we present a 66-year-old man with continent cutaneous pouch after radical cystoprostatectomy that presented with spontaneous perforation 25 years after surgery. Spontaneous pouch perforation in our case after 25 years emphasizes the need for long follow-up in patients with continent diversion.
\end{abstract}

Implication for health policy/practice/research/medical education:

Spontaneous rupture of a continent cutaneous urinary diversion is uncommon and diagnosis of this situation requires a high degree of suspicion and emphasizes the need for long follow-up in patients with continent diversion.

Please cite this paper as: Hosseini SY, Dehghani MD, Afsharimoghaddam A, Sepehri Z, Afshari M. Spontaneous rupture of continent cutaneous urinary diversion after 25 years. J Renal Inj Prev. 2017;6(2):80-82. doi: 10.15171/jrip.2017.15

\section{Introduction}

The 7 th most common malignancy in males and 17 th in females is bladder cancer $(1,2)$. The best treatment in cases with localized muscle invasive tumor as well as cases with high grade non-muscle invasive bladder cancer is radical cystectomy (3-6).

While orthotopic bladder replacement is accepted as a diversion method, but continent cutaneous pouch for reconstruction of the lower urinary tract is a good option in suitable cases after radical cystectomy (7) and the use of detubularized ileum has wide acceptance (8).

Some complications which are specifically associated to catheterizable cutaneous pouch consist of catheterizing difficulties, stenosis of stoma, stones, stricture of ureterointestinal anastomosis, and ultimately pouch rupture. Majority of complications take place in the first three years after surgery however, rarely some events may occur many years after the operation $(9,10)$.
Spontaneous perforation of continent cutaneous urinary diversion is an absolute rare event; yet it is a welldocumented complication after reconstruction of lower urinary tract (11).

\section{Case Presentation}

A 66-year-old man presented to the emergency ward complaining of fatigue, malaise and abdominal pain without signs of generalized peritonitis from two days ago. The patient was ill and conscious - but not toxic - without any fever or changes in blood pressure and heart rate. The patient experienced unwillingness drinking and eating and simultaneously decrease in urine output. Laboratory data showed increasing in blood urea nitrogen (BUN) and creatinine $(\mathrm{Cr})$ with mild metabolic acidosis. Serum Cr: $1.9 \mathrm{mg} / \mathrm{dL}, \mathrm{BUN}$ : $71 \mathrm{mg} / \mathrm{dL}$, ph: 7.24, PHCO3: $11 \mathrm{~mm} \mathrm{Hg}$ and Pco2 was $33 \mathrm{~mm} \mathrm{Hg}$. Ultrasonography of abdomen and pelvis revealed no hydronephrosis, however some 
intraabdominal free fluid was detected.

He had a continent cutaneous urinary diversion with detubularized ileum due to radical cystoprostatectomy 25 years ago after diagnosis of muscle invasive bladder cancer.

After the surgery, clean intermittent catheterization (CIC) has been conducted every 6 hours to make empty his neobladder. During the first year post-surgery, he has under follow up surveillance and there were no metastasis and tumor recurrence during this period, however he abandoned follow up and had experienced no problem for 25 years until 2 days ago.

At entrance immediately hydration and antibiotic therapy started and a 16 Fr Foley catheter gently inserted in the pouch through the cutaneous stoma and ultimately only $500 \mathrm{~mL}$ of urine was drained. Examination revealed periumbilical pain and tenderness without rebound tenderness. Patient mentioned no defecation or gas passage during last 2 days. A computed tomography (CT) with oral contrast revealed no bowel obstruction, while it also indicated intraabdominal free fluid as like ultrasonographic findings (Figure 1). The CT-pouchography was conducted and confirmed extravasation of contrast media from the pouch (Figure 2).

While on conservative managements, his abdominal distention and decreasing in urinary output was

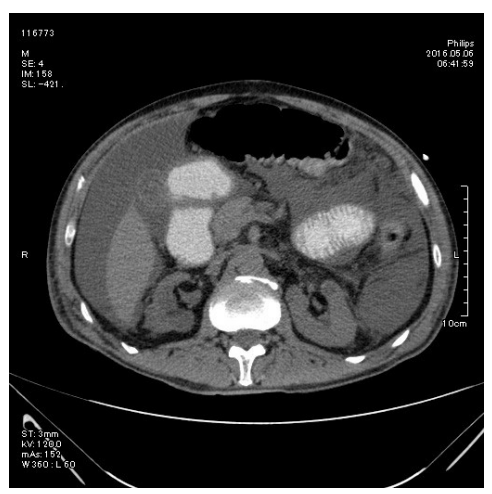

Figure 1. Intra-abdominal free fluid in the oral contrast-computed tomography without bowel obstruction.

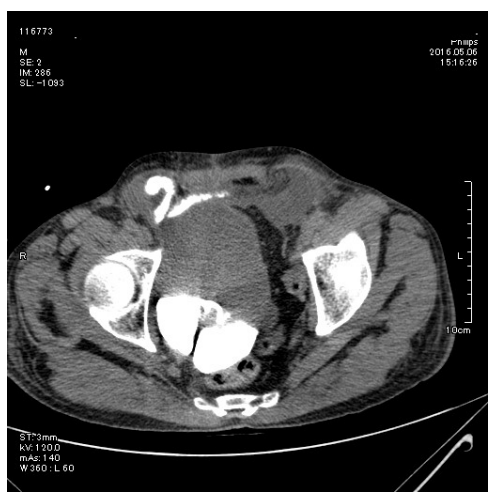

Figure 2. Eextravasation of contrast media in the CTpouchography progressed, we decided to explore the abdomen. At laparotomy a $2 \mathrm{~cm}$ defect in left anterior side of the pouch was detected and repaired.

His postoperative course was passed without any complication and he discharged one week after surgery while, Foley catheter remained inside the pouch via the cutaneous stoma. After three weeks Foley catheter was removed and he continued CIC.

\section{Discussion}

Complication rate is high in urinary diversion even after 5 years; Scott et al concluded that the patients should be informed of complications and they should be under followed up as tightly as for cancer follow up (12). Accordingly Richard et al, concluded that, radical cystectomy and subsequent urinary diversion is the most difficult urologic surgery, and the complications may occur even after 20 years (13).

Spontaneous rupture of continent urinary diversion is extremely rare late complication though in some studies this complication is not even reported at all (14). In fact, the exact incidence of spontaneous perforation of continent cutaneous urinary diversion is not really understood (15-18).

The rate of complications should be chronically evaluated while the proportion of patients decrease during the following years, hence it might be underestimated years or decades after surgery (13).

Mansson et al detected a higher rate of neobladder perforation in continent cutaneous urinary diversion than orthotopic pouches, while there is no pop-off mechanism in the former. The incidence of perforation in this report is $1.5 \%$ and there is no difference between colonic or ileal pouches in perforation rate. Although there was a perforation in appendiceal outlet in one case (16).

Most complications of radical cystectomy and urinary diversion is related to the urinary diversion section. Although the literature reports all complications are the same for the two procedures (15).

Some crucial contributing factors for rupture are possible weakening and ischemic changes of pouch wall due to acute or chronic over-distention of continent diversion (17).

Patients may present with some symptoms such as localized pain around stoma or mild to severe generalized abdominal pain or signs of frank peritonitis, sepsis, ileus and fever. Admittedly diagnosis needs a high degree of suspicion. Computed tomography with pouchography is possibly a better option for imaging.

Furthermore, several reports of conservative management with catheter drainage, and wide spectrum antibiotic therapy in literature were reported (18), however in the presence of generalized peritonitis or progressing and worsening patient's condition (abdominal distention, fever, oliguria, etc.) laparotomy is mandatory.

\section{Conclusion}

Spontaneous pouch perforation in our case after 25 years emphasizes the need for long follow-up in patients with 
continent diversion. Sudden onset of abdominal pain in a patient with continent pouch (orthotopic or cutaneous) should be considered rupture until proven otherwise. To our knowledge, this is the latest spontaneous pouch perforation that reported till now.

\section{Acknowledgments}

Authors would like to thank Dr. Zohre Kiani for his invaluable comments on the manuscript.

\section{Authors' contribution}

SYH; conceived the study. MD; participated in design and coordination of the study. AFM; collected data and wrote first draft. ZS; helped in data collection and drafting the manuscript from beginning to the last point. MA; read and approved the final version of manuscript. All authors also read and approved the final manuscript.

\section{Conflicts of interest}

The authors declare no conflict of interest.

\section{Ethical considerations}

Ethical issues (including plagiarism, data fabrication, double publication) have been completely observed by the authors. Written consent was obtained from the patient for publication of the study.

\section{Funding/Support}

None.

\section{References}

1. Colombel M, Soloway M, Akaza H, Böhle A, Palou J, Buckley R, et al. Epidemiology, Staging, grading, and risk stratification of bladder cancer. Eur Urol Suppl. 2008;7: 618-26. doi: 10.1016/j.eursup.2008.08.002.

2. Kirkali Z, Chan T, Manoharan M, Algaba F, Busch C, Cheng L, et al. Bladder cancer: epidemiology, staging and grading, and diagnosis. Urology. 2005;66:4-34. doi: 10.1016/j. urology.2005.07.062.

3. Babjuk M, Oosterlinck W, Sylvester R, Kaasinen E, Böhle A, Palou-Redorta J, et al. EAU guidelines on non-muscleinvasive urothelial carcinoma of the bladder. Eur Urol. 2008;54:303-14. doi: 10.1016/j.eururo.2008.04.051.

4. Van Rhijn BW, Burger M, Lotan Y, Solsona E, Stief CG, Sylvester RJ, et al. Recurrence and progression of disease in non-muscle-invasive bladder cancer: from epidemiology to treatment strategy. Eur Urol. 2009;56:430-42. doi: 10.1016/j. eururo.2009.06.028.

5. De Nunzio C, Carbone A, Albisinni S, Alpi G, Cantiani A, Liberti $M$, et al. Long-term experience with early single mitomycin $\mathrm{C}$ instillations in patients with low-risk non- muscle-invasive bladder cancer: prospective, single-centre randomised trial. World J Urol. 2011;29:517-21. doi: 10.1007/s00345-011-0691-2.

6. Gschwend JE, Retz M, Kuebler H, Autenrieth M. Indications and oncologic outcome of radical cystectomy for urothelial bladder cancer. Eur Urol Suppl. 2010;9:10-8.

7. Kreder KJ, Stone AR. Urinary Diversion: Scientific Foundations and Clinical Practice. 2nd ed. London: Taylor \& Francis; 2005.

8. Martins FE, Bennett CJ, Skinner DG. Options in replacement cystoplasty following radical cystectomy: high hopes or successful reality. J Urol. 1995;153:1363-72.

9. Wiesner C, Bonfig R, Stein R, Gerharz EW, Pahernik S, Riedmiller $\mathrm{H}$, et al. Continent cutaneous urinary diversion: long-term follow-up of more than 800 patients with ileocecal reservoirs. World J Urol. 2006;24:315-8. doi: 10.1007/s00345-006-0078-y.

10. Abdallah MM, Bissada NK, Hamouda HM, Bissada AN. Long-term multi-institutional evaluation of Charleston pouch I continent cutaneous urinary diversion. J Urol. 2007;177:2217-20. doi: 10.1016/j.juro.2007.01.142.

11. Rosenberg S, Gofrit ON, Hidas G, Landau EH, Pode D. Diagnosing spontaneous ileal neobladder perforation: too often delayed. Can Urol Assoc J. 2013;7:E817-9. doi: 10.5489/cuaj.1531.

12. GilbertSM, Lai J, SaigalCS, GoreJL. Downstream complications following urinary diversion. J Urol. 2013;190:916-22. doi: 10.1016/j.juro.2013.03.026.

13. Hautmann RE, Abol-Enein H, Davidsson T, Gudjonsson S, Hautmann SH, Holm HV, et al. ICUD-EAU International Consultation on Bladder Cancer 2012: Urinary Diversion. Eur Urol. 2013;63:67-80. doi: 10.1016/j.eururo.2012.08.050.

14. Torrey RR, Chan KG, Yip W, Josephson DY, Lau CS, Ruel NH, et al. Functional outcomes and complications in patients with bladder cancer undergoing roboticassisted radical cystectomy with extracorporeal Indiana pouch continent cutaneous urinary diversion. Urology. 2012;79:1073-8. doi: 10.1016/j.urology.2011.12.050

15. Hautmann R, de Petriconi R, Volkmer BG. Lessons learned from 1,000 neobladders: the 90-day complication rate. J Urol. 2010;184:990-4. doi: 10.1016/j.juro.2011.02.006.

16. Mansson W, Bakke A, Bergman B, Brekkan E, Jonsson O, Kihl B, et al. Perforation of continent urinary reservoirs. Scandinavian experience. Scand J Urol Nephrol. 1997;31:529-32.

17. Desgrandchamps F, Cariou G, Barthelemy Y, Boyer C, Teillac P, Le Duc A, et al. Spontaneous rupture of orthotopic detubularized ileal bladder replacement: report of 5 cases. J Urol. 1997;158:798-800. doi: 10.1097/00005392199709000-00028.

18. Singh S, Choong S. Rupture and perforation of urinary reservoirs made from bowel. World J Urol. 2004;22:222-6. doi: $10.1007 /$ s00345-004-0439-3.

Copyright $\odot 2017$ The Author(s); Published by Nickan Research Institute. This is an open-access article distributed under the terms of the Creative Commons Attribution License (http://creativecommons.org/licenses/by/4.0), which permits unrestricted use, distribution, and reproduction in any medium, provided the original work is properly cited. 